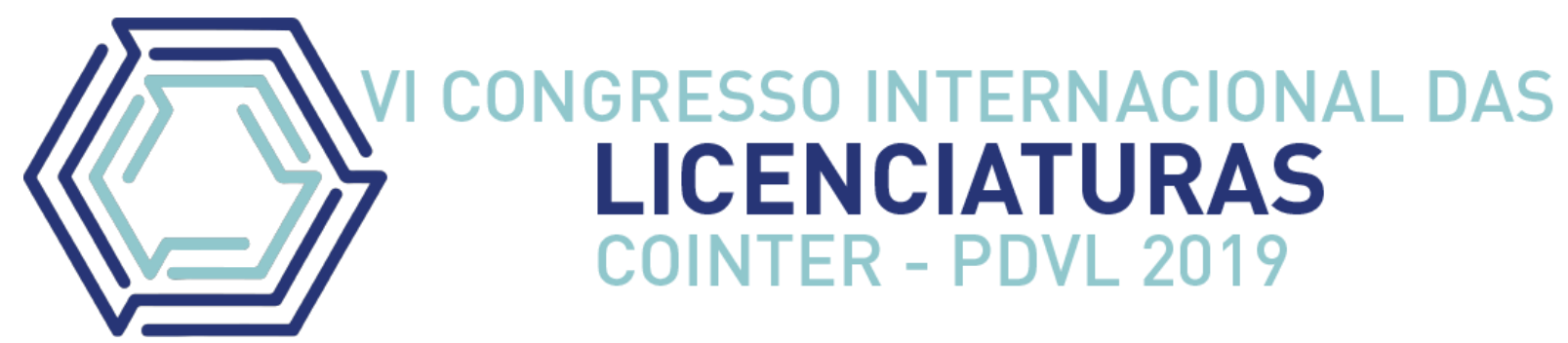

\title{
PROCESSOS DE ENSINO APRENDIZAGEM EM EAD PARA DESENVOLVER A AUTONOMIA
}

\author{
ENSEÑANZA DE PROCESOS DE APRENDIZAJE PARA DESARROLLAR LA \\ AUTONOMÍA
}

\section{TEACHING LEARNING PROCESSES TO DEVELOP AUTONOMY}

\author{
Apresentação: Comunicação Oral \\ Tainá da Silva Veras ${ }^{1}$; Shakira Santos Rodrigues²; João Pedro Nogueira Vieira ${ }^{3}$; Julio Cesar \\ Costa de Macedo ${ }^{4}$ Ramásio Ferreira de Melo ${ }^{5}$
}

\section{DOI: https://doi.org/10.31692/2358-9728.VICOINTERPDVL.2019.0112}

\section{Resumo}

A educação a distância (EaD) não é uma modalidade nova, mas a nova era desse tipo de educação é voltada para a tecnologia e economia de tempo, sendo que não exige a presença do aluno em uma determinada hora, podendo se realizar as atividades nos tempos disponíveis e com calma. Objetivamos analisar as plataformas ofertantes de cursos de $\mathrm{EaD}$, desenvolver as habilidades de aprendizagem de forma autônoma de cada aluno dessa modalidade de ensino, instigar o egresso nos cursos de EaD, praticar ações de ensino aprendizagem e ajudar na construção da autonomia dos alunos ingressos nesses cursos. A educação é um direito de todos e está previsto em lei, incluindo o uso de recursos tecnológicos para a disseminação do conhecimento. A metodologia utilizada para elaboração deste artigo é resultada de uma pesquisa aplicada, que aborda o problema de forma qualitativa e quantitativa ao analisar os dados bibliográficos e os dados coletados por meio de um questionário enviado por e-mail aos alunos de EaD, a escolha dos participantes foi de forma aleatória, não escolhemos alunos de uma faculdade especifica para a tabulação de dados.Nos resultados observa-se que os alunos disponibilizam algum tempo para estudar, visitam as plataformas e fazem uso de recursos tecnológicos nas pesquisas, são alunos autônomos, mas ainda sim encontram dificuldades em meio ao curso que são inscritos. Com esse estudo pode-se perceber que a autonomia na educação a distância é um processo longo e árduo, que é conquistado com o tempo, por muitos é visto como uma obrigação, porém não deve ser encarado dessa forma quando se trata de educação. Portanto, cada caso deve ser estudado e analisado cautelosamente, pois em um mesmo curso e plataforma, existem diversos tipos de alunos e modos diferentes de aprendizado, mas a autonomia deve ser despertada em conjunto, para que se tenha um

\footnotetext{
${ }^{1}$ Licenciatura em Computação, Instituto Federal do Tocantins (IFTO), E-mail: tainasilvaveras@gmail.com

2 Licenciatura em Computação, Instituto Federal do Tocantins (IFTO), E-mail: shakirasantosrodrigues@gmail.com

${ }^{3}$ Licenciatura em Computação, Instituto Federal do Tocantins (IFTO), E-mail: jpedronogueira94@gmail.com

${ }^{4}$ Licenciatura em Computação, Instituto Federal do Tocantins (IFTO), E-mail: juliocesar1076@gmail.com

${ }^{5}$ Mestre em educação, Instituto Federal do Tocantins (IFTO), E-mail: ramasio.ml@gmail.com
} 
aproveitamento do curso e uma boa formação profissional.

Palavras-Chave:Educação a distância, tecnologia, autonomia.

\title{
Resumen
}

La educación a distancia (DE) no es una modalidadnueva, pero lanueva era de este tipo de educación se centra enlatecnología y elahorro de tiempo, y no requierela presencia delestudianteenun momento determinado, y lasactividades se pueden realizar enelTiemposdisponibles y tranquilo. Nuestro objetivo es analizarlas plataformas que ofrecen cursos de educación a distancia, desarrollarlas habilidades de aprendizaje de forma autónoma de cada estudiante de este tipo de educación, instigar lasalidaenlos cursos de educación a distancia, practicarelaprendizaje de acciones de enseñanza y ayudar a construir laautonomía de losestudiantes que ingresan a estos cursos. . La educación es underecho de todos y está prevista por laley, incluidoel uso de recursos tecnológicos para ladifusióndelconocimiento. La metodología utilizada para elaborar este artículo es el resultado de una investigación aplicada, que aborda el problema de forma cualitativa y cuantitativa mediante elanálisis de losdatos bibliográficos y losdatos recopilados a través de uncuestionario enviado por correo electrónico a losestudiantes de $\mathrm{DE}$, laelección de los participantes fueron al azar, no elegimosestudiantes de una universidad específica para latabulación de datos. Los resultados muestran que losestudiantestomantiempo para estudiar, visitar las plataformas y hacer uso de los recursos tecnológicos ensuinvestigación, sonestudiantes autónomos, pero aúnencuentrandificultadesenel curso enel que están inscritos. Con este estudio se puede ver que laautonomíaenlaeducación a distancia es unproceso largo y arduo, que se logra coneltiempo, es visto por muchos como una obligación, pero no debe verse de esta maneracuando se trata de laeducación. Por lo tanto, cada caso debeestudiarse y analizarse cuidadosamente, porque enelmismo curso y plataforma hay diferentes tipos de estudiantes y diferentes formas de aprendizaje, pero laautonomíadebedespertarse juntos, para que el curso puedadisfrutarse y ser bueno. formaciónprofesional.

Palabras Clave:Educación a distancia, tecnología, autonomía.

\begin{abstract}
Distanceeducation (DE) isnot a new modality, butthe new age ofthistypeofeducationisfocusedontechnologyand time saving, and does notrequirethepresenceofthestudentat a certain time, andactivitiescanbeperformed in the times availableandcalm. Weaimtoanalyzetheplatformsofferingdistanceeducationcourses, developthelearning skills autonomouslyofeachstudentofthistypeofeducation, instigatetheegress in thecoursesofdistanceeducation, practiceteachingactionslearningand help build

theautonomyofstudentsenteringthesecourses. .Educationiseveryone'srightandisprovidedbylaw, includingthe use oftechnologicalresources for thedisseminationofknowledge. The methodologyusedtoelaboratethisarticleistheresultofanappliedresearch,

whichaddressestheproblem in a qualitativeandquantitativewaybyanalyzingthebibliographic data andthe data collectedthrough a questionnairesentby e-mail tothestudentsof DE, thechoiceofparticipantswasatrandom, wedidnotchoosestudentsfrom a specificcollege for data tabulation. The results show thatstudents take time tostudy, visittheplatformsand make use oftechnologicalresources in theirresearch. They are autonomousstudents, butthey still encounterdifficulties in thecoursethey are enrolled. Withthisstudy it canbeseenthatautonomy
\end{abstract}


in distanceeducationis a longandarduousprocess, whichisconquered over time, isseenbymany as anobligation, butshouldnotbeviewedthiswaywhen it comes toeducation. Therefore, each case shouldbestudiedandanalyzedcarefully, because in thesamecourseandplatformthere are differenttypesofstudentsanddifferentwaysoflearning, buttheautonomy must beawakenedtogether, sothatthecoursecanbeenjoyedandgood. professional qualification

Keywords: Distanceeducation, technology, autonomy.

\section{Introdução}

Na Educação a Distância a autonomia do aluno remete a liberdade e independência na forma de aprendizagem, diversas variáveis contribuem para o sucesso da disseminação desse pilar educacional na EAD em que uma delas é a autonomia do aluno, porém os alunos que buscam essa modalidade de ensino demonstram não terem preparo para enfrentar os desafios exigidos dos cursos à distância, que por sua vez gera a evasão destes cursos.

Autonomia não é um conceito pedagógico da EAD, isto é, não está relacionada ao aspecto da estrutura física de ambiente cujos personagens se encontram, como por exemplo, a sala de aula. E nem de algum manual pedagógico. Autonomia é compreendido como o poder de determinar a si próprio a lei. "Etimologicamente autonomia é a condição de uma pessoa ou de uma coletividade cultural, que determina ela mesma a lei à qual se submete" (LALANDE, 1999). Desta forma, autonomia é muito mais do que um projeto pedagógico. Autonomia aqui abrange o campo vida das pessoas. Autonomia associa-se a educação no compreender do que seja o esclarecimento - "linha filosófica caracterizada pelo empenho de estender a crítica e o guia da razão em todos os campos da experiência humana" (ABBAGMANO, p. 509, 1962).

O aluno de EAD deve ser autônomo e desempenhar um papel ativo na construção do seu próprio conhecimento, deve possuir iniciativa, pensamento crítico e ser capaz de gerenciar e monitorar o seu próprio processo de aprendizagem, além de saber organizar o tempo e ter disciplina para o estudo. Na construção do desenvolvimento do aluno, de forma que o mesmo se torne autônomo quanto ao seu aprendizado, necessita-se de acompanhamento do tutor e uma plataforma acessível e de fácil manuseio. Para isso se subtende que o aluno precisa de um ensino de qualidade para poder desenvolver suas habilidades e ter sucesso na sua aprendizagem.

\section{Fundamentação Teórica}

O decreto 5622/05, que regulamenta o Art. 80 da Lei de Diretrizes e Bases (LDB), em seu Art. $1^{\circ}$ define a educação a distância como: uma modalidade educacional na qual a 
mediação didático-pedagógica nos processos de ensino e aprendizagem ocorre com a utilização de meios e tecnologias de informação e comunicação, com estudantes e professores desenvolvendo atividades educativas em lugares ou tempos diversos. A partir desta definição é possível perceber que a EAD, a exemplo da educação presencial ocorre a partir da interação de quatro elementos importantes: o espaço, o tempo, os alunos e professores e a utilização de meios e tecnologias de comunicação. O que, então, diferencia a educação a distância da educação presencial? A EAD está inserida num contexto chamado cibercultura, que segundo Levy (1997) "é um conjunto de técnicas, práticas, atitudes, modos de pensamento e valores que se desenvolvem paralelamente ao crescimento do ciberespaço (um espaço de comunicação possibilitado pela interconexão mundial de computadores)."

A educação a distância é uma oportunidade de graduação para aquelas pessoas que não tem uma disponibilidade de tempo, e para se deslocar até uma instituição de ensino, sendo de fácil acesso, contendo inúmeras plataformas de ensino e variados cursos, de módulos diferentes, uma boa opção para quem quer se formar em pouco tempo e sem sair de casa. Segundo Pareschi e Martini (2017), “Os recursos tecnológicos passam a ser instrumentos incentivadores do aprendizado, tendo como intuito a interação entre os alunos. O ciberespaço se apresenta como o lócus de comunicação, sociabilidade, informação, conhecimento e educação. Nessa realidade EAD, permeada pela utilização das TICs, a palavra "autonomia" se apresenta como uma ordem." O desenvolvimento da autonomia consiste em uma árdua tarefa de aprendizado de modo em que o aluno necessita estudar sozinho, apenas com o auxílio do material disponibilizado a ele, muitas vezes até mesmo sem a ajuda do tutor.

De acordo com Ribeiro e Carvalho (2012), “a EAD é vista atualmente como um mecanismo capaz de contribuir no processo de formação inicial e continuada dos estudantes, proporcionando-lhes a capacidade de formação da autonomia acadêmica, uma vez que a autoaprendizagem é dos fatores essenciais de sua realização.” O que reforça a abordagem inicial sobre a necessidade de se aprender de forma independente, além de se tornar um aluno de qualidade, poderá ingressar no mercado de trabalho com facilidade, devido ao esforço apresentado apenas na graduação.

Para se desenvolver a autonomia precisa de vontade e auto ajuda, o incentivo interior é um fator determinante nesse processo, deverá ter consciência de que fará o curso totalmente sozinho, tendo ou não o auxílio de um tutor, então terá de ler, interpretar, ouvir, assistir a vídeos aulas, fazer pesquisas aprofundadas sobre o assunto, para que não fique apenas nos 
materiais disponibilizados e possa ter uma ampla visão sobre o assunto abordado, principalmente na EAD é de extrema importância que o aluno desenvolva suas capacidades cognitivas na aprendizagem nesse tipo de ensino, Ribeiro e Carvalho (2012), "O aluno deve desenvolver a capacidade de autonomia para garantir a condução e a efetivação de sua aprendizagem, uma vez que não dispõe diretamente do acompanhamento presencial do professor, para realizar seus estudos e construir o conhecimento. Por isso, há a ideia de que o aluno da EAD tem maior oportunidade de desenvolvimento de leitura, análise, interpretação de textos científicos e, consequentemente a capacidade investigativa no processo de aprendizagem.".

É importante pensar como os papéis docentes que surgem no contexto da sala de aula virtual contribuem para a construção da cidadania. Lacerda (2011, p. 3) afirma que "o principal papel da educação reside na preparação do indivíduo para, autonomamente, saber buscar informações e transformá-las nos conhecimentos de que ele necessita, no momento em que for preciso e da forma mais criativa possível". Isso pode ser traduzido na ideia do que seja de fato uma educação que atenda às necessidades cotidianas, que contribui para a formação de cidadãos com atitudes diante das demandas sociais e individuais. Isso pressupõe autoria, já que o ensino aprendizagem, assim concebida, requer a intervenção na obra e não apenas a contemplação imaginada separada da proposição.

Segundo SABBATINI (2013), A tecnologia vem ao socorro de uma "educação autêntica", pela construção coletiva do conhecimento através de comunidades virtuais nas quais a história, a cultura e os valores do educando seriam não somente reconhecidos, mas utilizados como elementos motores do processo de ensino. A EAD é uma modalidade de ensino que através dos recursos tecnológicos ajuda os discentes a terem diferentes formas de pensar, trabalhar, pesquisar, possibilitando a autonomia flexibilizar seus estudos, formando assim uma relação entre os indivíduos com o objetivo de aprenderem juntos, tendo como base a pesquisa e o diálogo para compartilhar conhecimento. $\mathrm{O}$ discente autônomo é capaz de se organizar frente ao processo de aprendizagem, sabendo quais são suas dificuldades e necessidades mediante ao processo de ensino, sabendo exatamente como deve agir para alcançar seu objetivo, pois a educação a distância é um processo complexo que exige total envolvimento e comprometimento de ambas as partes.

O aluno em EAD precisa ter domínio das habilidades necessárias para exercer efetivamente as práticas sociais de leitura e escrita, é imprescindível para que assim tenha 
condições para aprender de forma autônoma, Soares (2015), “Como ele poderá construir essa autonomia sem ter esse domínio da leitura e da escrita, o ensino a distância é mediado através das tecnologias de comunicação e, consequentemente, faz uso de diferentes gêneros textuais, o que também exige novas competências para interagir com essas novas tecnologias da escrita.".

Na pedagogia da autonomia, traz uma reflexão sobre ensinar, para que o aluno possa ter autonomia: "O respeito à autonomia e à dignidade de cada um é um imperativo ético e não um favor que podemos ou não conceder uns aos outros. O professor que desrespeita a curiosidade do educando, o seu gosto estético, a sua inquietude, a sua linguagem, mais precisamente, a sua sintaxe e a sua prosódia; o professor que ironiza o aluno, que minimiza, que manda que "ele se ponha em seu lugar" ao mais tênue sinal de sua rebeldia legitima, tanto quanto o professor que se exige do cumprimento de seu dever de ensinar, de estar respeitosamente presente à experiência formadora do educando, transgredem os princípios fundamentalmente éticos de nossa existência.”. (FREIRE, 2002, p. 59).

O pensamento Freireano supõe um ensino voltado ao diálogo, à liberdade e a uma busca constante do conhecimento participativo e transformador, em que o ser humano é entendido como sujeito de sua própria aprendizagem, e não como mero objeto passivo e heterônomo diante do saber. Hoje na sociedade do conhecimento faz-se necessário então, construir e talvez reconstruir os novos rumos dessa educação cidadã, dinâmica, libertadora, autônoma, consciente e popular, respaldando o aprendizado para a vida, procurando orientar o aluno para uma via de produção coletiva, mas desenvolvendo a autonomia em cada um.(LINARD, 2000).

Wissmann (2006) afirma que "a autonomia do aprendiz requer não só a aprendizagem, mas aprender a aprender”. Entretanto, a concepção de autonomia, segundo o autor, pode ser entendida como produto de um processo interativo definido pela essência interdependente de cada indivíduo como ser social que é, autonomia do aluno revela sua capacidade de organizar sozinho os seus estudos, com independência do professor, administrando eficazmente o seu tempo de dedicação no aprendizado e escolhendo de forma eficiente as fontes de informação disponíveis.

\section{Metodologia}

Este artigo é o resultado de uma pesquisa aplicada, que aborda o problema de forma 
qualitativa e quantitativa ao analisar os dados bibliográficos e os dados coletados por meio de um questionário enviado por e-mail aos alunos de EAD, a escolha dos participantes foi de forma aleatória, não escolhemos alunos de uma faculdade especifica para a tabulação de dados. O questionário aplicado teve como finalidade definir o perfil dos participantes, identificar as concepções sobre o EAD e caracterizar como tem sido a prática nesta modalidade de ensino. Sendo priorizados artigos científicos que tratam principalmente da autonomia do aluno de educação a distância, porém foi-se utilizada as experiencias próprias com esse tipo de ensino, podendo ter uma ampla visão, não só na teoria como também na prática. Utilizamos o modo de pesquisa de caso de uso, tendo como fontes autores como Lalande, Abbagmano, Abadi e Rehfeldt, Serafini, Freire, Linard, Sabbatini, entre outros, que explanaram sobre a autonomia em EAD. Foram utilizadas ferramentas tais como notebook e internet, com acesso há algumas plataformas de educação a distância gratuitas, para abranger a visão dessas plataformas, analisar a metodologia de ensino e como é aplicado.

\section{Resultados e Discussão}

Através dos dados coletados e considerando os pontos levantados, as respostas foram para análise, tendo em mente as questões de pesquisa definidas. Assim obtivemos os resultados do questionário aplicado online, tivemos um total de 09 respostas onde foram analisadas e explicadas.

Gráfico 01.Quantas horas por semana você se dedica a estudar?

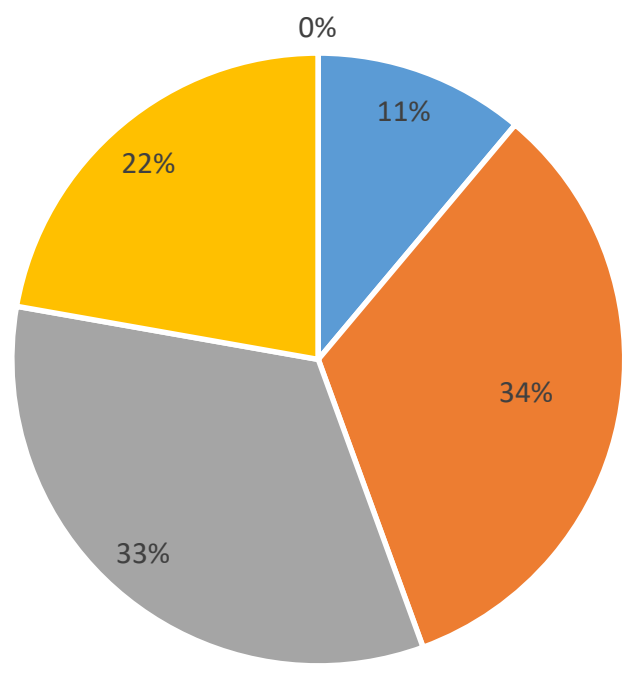

- Nenhuma

- Entre 1 e 2 horas

- Entre 2 a 4 horas

- Entre 4 a 6 horas

- Mais de 6 horas

Fonte: Própria (2018) 
A autoaprendizagem trata-se de um processo de adquirir conhecimentos, habilidades e atitudes, que o indivíduo realiza por conta própria, seja através do estudo ou de experiências. E um indivíduo é considerado autônomo quando tem capacidade de administrar e gerenciar seus compromissos e atividades, no gráfico podemos ver que os discentes organizam seus horários de estudos da melhor maneira que lhe convém. No entendimento de Preti (2000), a autoaprendizagem está diretamente relacionada à autonomia do estudante de EAD no seu processo de aprendizagem e deve ser buscada, exercitada e integrada no cotidiano das atividades profissionais e pessoais para que se torne algo próprio do sujeito.

Gráfico 02. Com qual frequência semanal você acessa o ambiente de ensino?

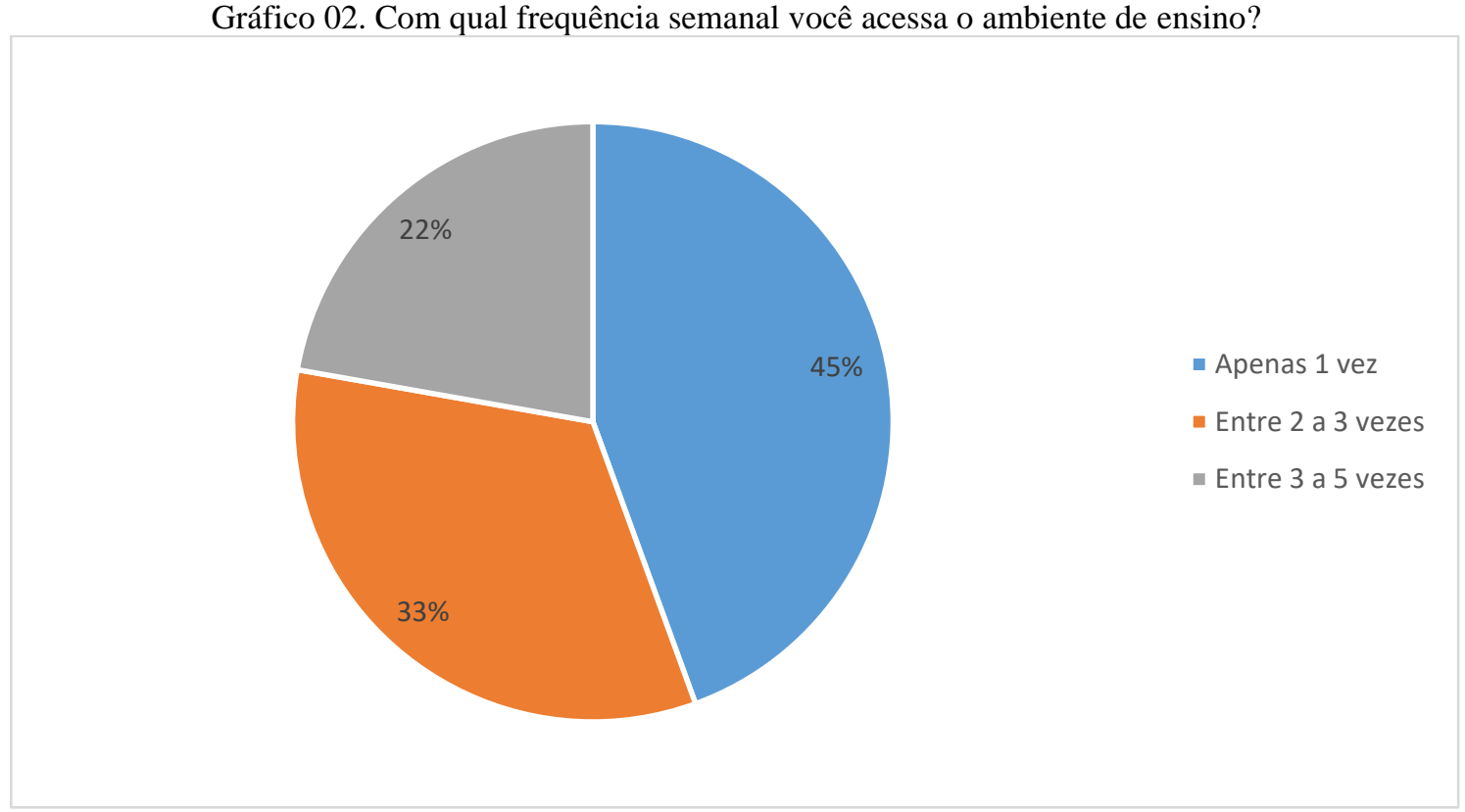

Fonte: Própria (2018)

Um ambiente colaborativo de aprendizagem visa possibilitar a construção de conhecimento por meio da comunicação entre diversos instrumentos, uma vez que estes propiciem o aprendizado de maneira colaborativa, onde todos podem e devem codificar e decodificar informações, visualizar novos caminhos e sugerir novos questionamentos, exercitando assim a autonomia, em um ambiente de ensino que os alunos não buscam se inteirar e se aperfeiçoar será basicamente impossível desenvolver autonomia. 
Gráfico 03. Você participa dos fóruns e compartilha saberes e experiências?

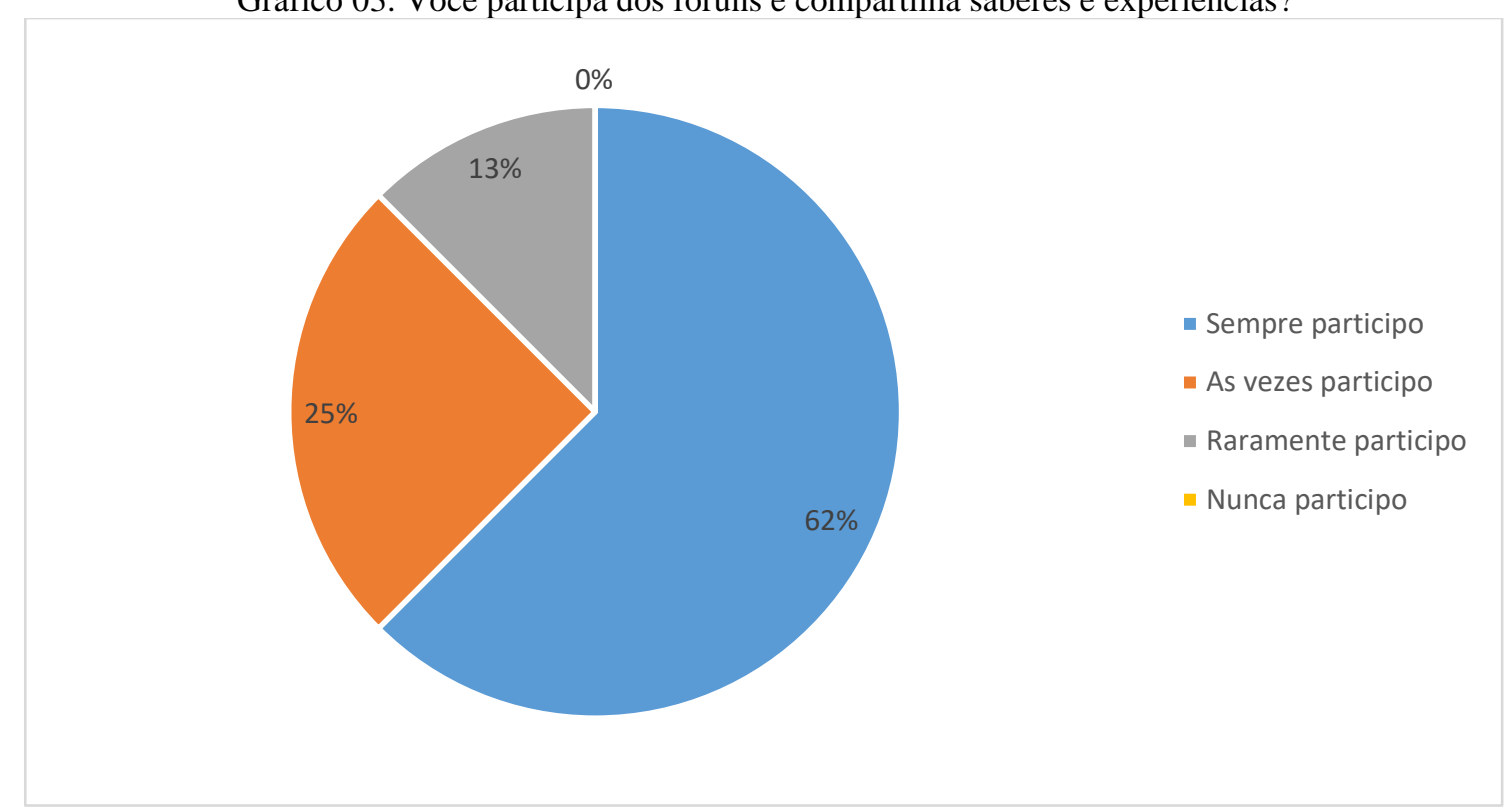

Fonte: Própria (2018)

A troca e a construção do conhecimento acontece por meio da interação mediada por várias relações. O processo de aprendizagem online deve ser exemplo de um espaço colaborativo, onde possa ocorrer a troca de conhecimento por meio de interação/mediação síncrona e assíncrona dos discentes e mediadores, por meio de ferramentas da web como ambientes virtuais.

Gráfico 04. Você como aluno se considera responsável com seu horário de estudos? 


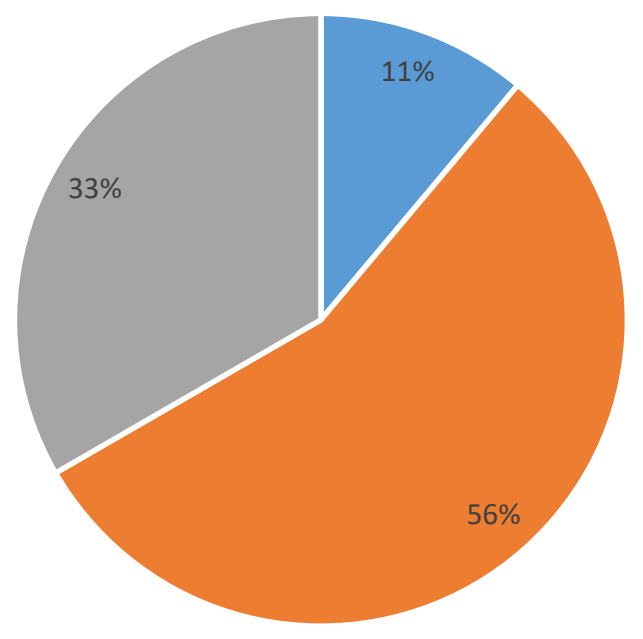

- Extremamente responsável

- Sou responsável

- Pouco responsável

Fonte: Própria (2018)

A autonomia está relacionada ao próprio indivíduo, à sua capacidade de buscar por si mesmo, reconhecer a "autonomia" no processo de ensino e de aprendizagem significa entender que o outro é independente, capaz de construir sozinho e que o professor formador e/ou tutor é o mediador do processo de aprendizagem.

Gráfico 05. Quais tecnologias você utiliza para estudar? (Pode marcar mais que uma opção)

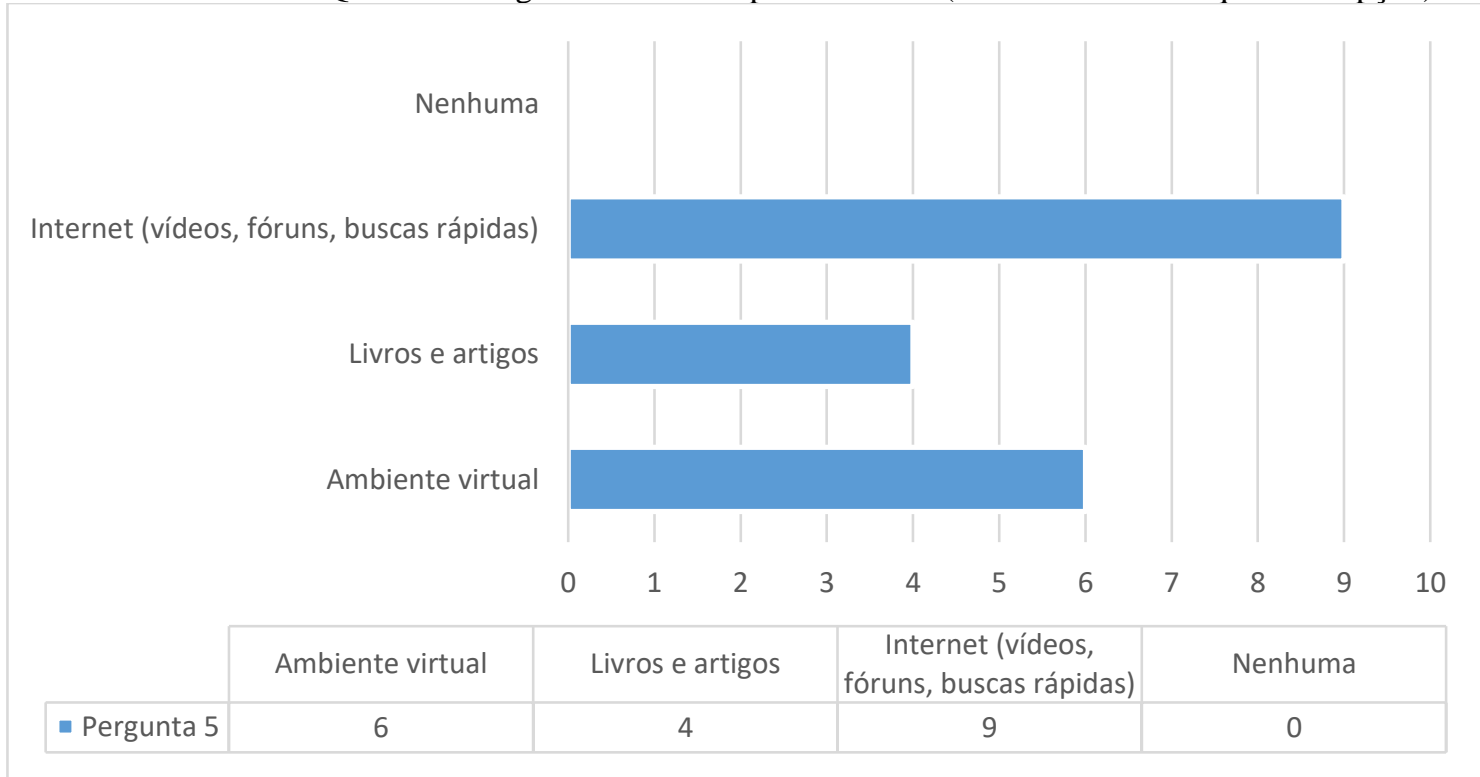

Própria (2018)

Fonte: 
No processo de aprendizagem autônoma, o estudante não é objeto ou produto, mas sujeito ativo que realiza sua própria aprendizagem e abstrai o conhecimento aplicando-o em situações novas, decidindo como e onde deve buscar o mesmo, da forma que se sentir melhor e tiver maior facilidade para abstrair o aprendizado.

Gráfico 06. Quando você tem dificuldades no entendimento de alguma disciplina, em que busca ajuda? (Pode marcar mais que uma opção).

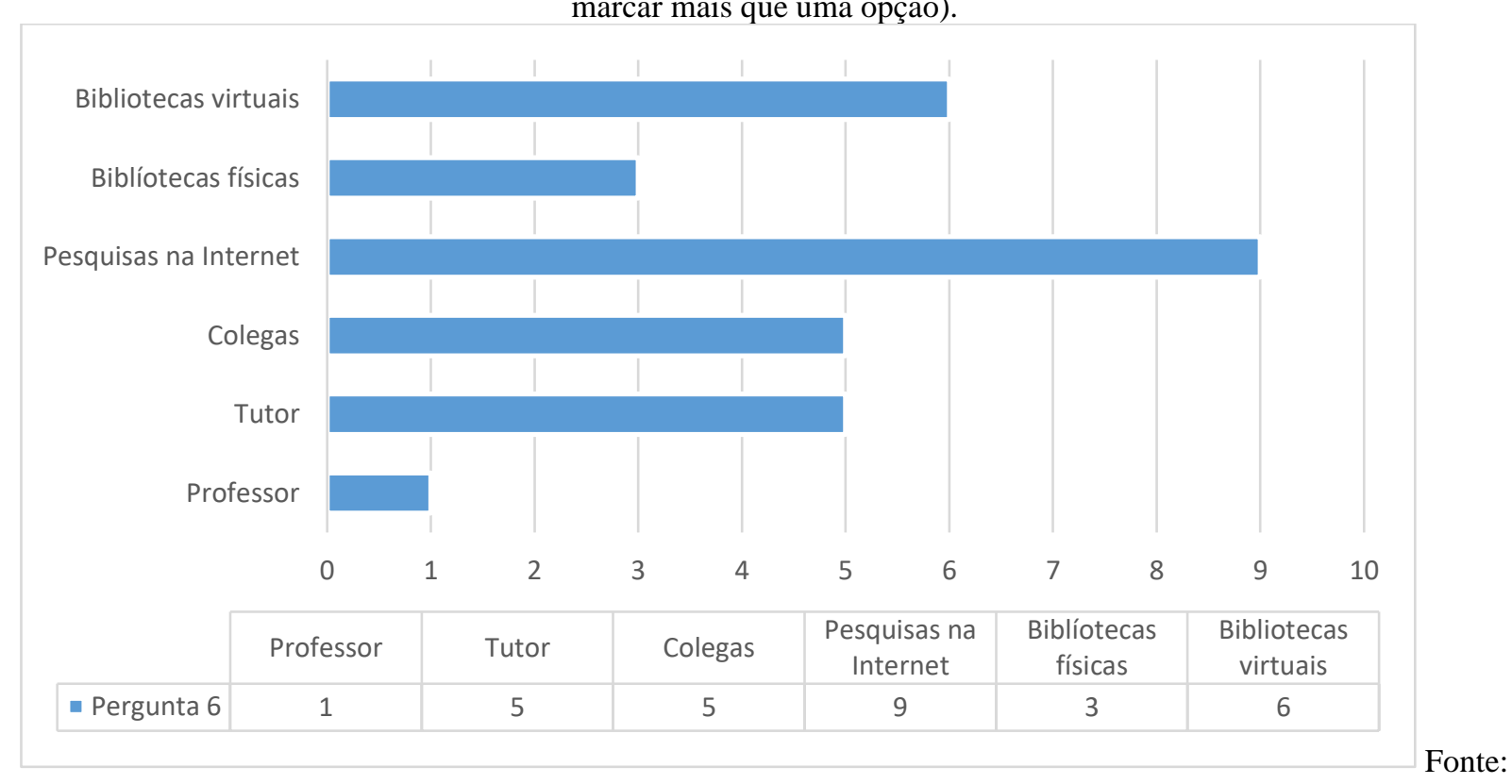

Própria (2018)

A ênfase na questão da autonomia exige das estudantes habilidades muitas vezes inexistentes, mas que podem ser adquiridas com dedicação, interesse e compromisso nos estudos, assim desenvolvendo a autonomia.

Tabela 01. Quais suas maiores dificuldades no curso EAD que frequenta?

\section{Descrição}




\begin{tabular}{|l|l|}
\hline Resposta 1 & O ambiente de ensino não é agradável. \\
\hline Resposta 2 & $\begin{array}{l}\text { Esclarecer dúvidas sobre os conteúdos com } \\
\text { os professores por meio do ambiente virtual. }\end{array}$ \\
\hline Resposta 3 & $\begin{array}{l}\text { Conciliar os horários de estudo e manter o } \\
\text { foco em estudar a distância. }\end{array}$ \\
\hline Resposta 4 & $\begin{array}{l}\text { Internet de péssima qualidade, } \\
\text { impossibilitando o acesso ao ambiente } \\
\text { virtual }\end{array}$ \\
\hline
\end{tabular}

Fonte: Própria (2018)

De acordo com os resultados apresentados na tabela 01, percebemos as principais dificuldades encontradas nos cursos em EAD, que vai da dificuldade de interação com os professores, conciliar os horários de estudo, o ambiente de ensino que não é agradável, entre outros.

Tabela 02. Para você o que significa ser um aluno autônomo em educação a distância?

\begin{tabular}{|l|l|}
\hline Resposta 1 & Descrição \\
\hline Resposta 2 & $\begin{array}{l}\text { Significa estudar o que precisa a qualquer } \\
\text { hora, fazer seu horário de estudos, ter } \\
\text { compromisso com os prazos e horários para } \\
\text { entrega de atividades, significa entender que } \\
\text { aprender com ensino a distância depende } \\
\text { bem mais da dedicação do aluno. }\end{array}$ \\
\hline Resposta 3 & $\begin{array}{l}\text { A partir do momento que se entra em um } \\
\text { curso EAD você se ver obrigado a ser } \\
\text { autônomo e autodidata. }\end{array}$ \\
\hline $\begin{array}{l}\text { Facilita bastante pra quem não pode } \\
\text { comparecer diariamente em uma faculdade } \\
\text { presencial. Ser um aluno dessa modalidade } \\
\text { apresenta diversos desafios. Há seus pontos } \\
\text { negativos e também positivos. Depende } \\
\text { muito da conciliação e disciplina do aluno, e } \\
\text { também de um conteúdo competente para } \\
\text { estar sendo estudado e aprendido. Afinal } \\
\text { vamos levar isso em toda trajetória } \\
\text { profissional. E o que acarretará ser um } \\
\text { profissional que fará a diferença no campo } \\
\text { atuante. }\end{array}$ \\
\hline
\end{tabular}

Fonte: Própria (2018)

Segundo a tabela 02 os entrevistados demonstram clareza do que é ser um aluno autônomo, entendem e apresentam habilidades de autonomia. Mesmo assim fica evidente que apesar de todos os esforços, os alunos têm diversas dificuldades. 


\section{Conclusões}

Com esse estudo pode-se perceber que a autonomia na educação a distância é um processo longo e árduo, que é conquistado com o tempo, por muitos é visto como uma obrigação, porém não deve ser encarado dessa forma quando se trata de educação. Os autores supracitados têm diversas e amplas visões sobre a autonomia dos alunos de EAD, deixando claro que o aluno é o responsável pelo seu aprendizado, com o uso das ferramentas síncronas e assíncronas, pois a comunicação com os demais colegas para troca de saberes é essencial no processo de ensino aprendizagem.

Para que se obtenham bons resultados no desenvolvimento da autonomia de cada aluno, as plataformas de EAD deveriam disponibilizar uma parte somente para dicas e melhorias nos cursos ofertados, dessa forma poderiam diminuir a evasão dos cursos, tornando a plataforma em um ambiente agradável no qual o aluno se sinta à vontade para fazer suas atividades e compartilhar seu conhecimento, pois teria um diferencial. Deve-se verificar todos os casos e reclamações, facilitando a melhoria do ensino e diminuindo o número de desistentes.

Portanto, cada caso deve ser estudado e analisado cautelosamente, pois em um mesmo curso e plataforma, existem diversos tipos de alunos e modos diferentes de aprendizado, mas a autonomia deve ser despertada em conjunto, para que se tenha um aproveitamento do curso e uma boa formação profissional em um ensino que não presencial, o uso de recursos visuais, jogos lúdicos e tecnológicos pode ajudar a aumentar o número de inscritos e formar novos profissionais com qualidade, pronunciando o melhoramento da educação a distância e promovendo-a a um novo patamar. 


\section{Referências}

BARBOSA, Alberto. Orientações pedagógicas via mídia impressa na ead: em direção à autonomia e criatividade.São Carlos - SP outubro/2016.Disponível em: > http://sistemas3.sead.ufscar.br < Acesso em: 20 de dezembro de 2018.

BRASIL, Ministério da Educação. Diretrizes Curriculares Nacionais para a Educação de Jovens e Adultos. Brasília, 2000. Disponível em: $<$ http://portal.mec.gov.br $>$ Acesso em: 10 de janeiro de 2019.

ELIA, Marcos; FERREIRA, Vanessa. Uma modelagem conceitual para apoiar a identificação das causas da evasão escolar em ead, Campinas-SP novembro/2013. Disponível em: >http://br-ie.org>Acesso em: 08 de janeiro de 2019.

MORAES, Reinaldo. As concepções e práticas do docente no ensino a distância, Natal RN outubro/2016. Disponível em: > http://www.editorarealize.com.br Acesso em: 16 de novembro de 2018.

OLIVEIRA, Maria Rosemary.Uso de tecnologias digitais, autonomia na aprendizagem e educação profissional a distância: uma possibilidade para a inclusão digital, São Carlos SP outubro/2016. Disponível em: > http://sistemas3.sead.ufscar.br < Acesso em: 16 de novembro de 2018.

PARESCHI, Claudinei Zagui; MARTINI, Claudinei José. “A autonomia na EaD”, Revista Educação em Foco, São Paulo, 2017. Disponível em: > revistaonline @ unifia.edu.br < Acesso 
em: 23 de novembro de 2018.

RIBEIRO, Raimunda Maria da Cunha; CARVALHO, Carmen Maria Cavalcante Nogueira de. "O desenvolvimento da autonomia no processo de aprendizagem em Educação a Distância (EAD)", Revista Aprendizagem em EAD - Ano 2012 - Volume 1 - Taguatinga DF outubro /2012 Disponível em: > http://portalrevistas.ucb.br/index.php/raead < Acesso em: 20 de novembro de 2018.

SABBATINI, Marcelo. O pensamento pedagógico de Paulo Freire e a Educação a Distância (EaD): aproximações entre dialogia, autonomia e emancipação através da Rede, Manaus - AM setembro/ 2013. Disponível em: > http://www.intercom.org.br/papers/nacionais/2013/resumos/R8-0631-1.pdf < Acesso em: 20 de novembro de 2018. 